\title{
The Lubricity Analysis of Cutting Fluid Emulsions
}

\author{
Erinéia da Silva Santos ${ }^{a}$, Ana Paula de Paula Camargo ${ }^{\prime}$, Edália Azevedo de Faria ${ }^{a}$, Francisco
}

\author{
Adriano Ferreira de Oliveira Junior ${ }^{a}$, Salete Martins Alves ${ }^{a *}$, Eduardo Lins de Barros Neto $^{a}$ \\ ${ }^{a}$ Universidade Federal do Rio Grande do Norte - UFRN, Campus Universitário, Lagoa Nova, CEP \\ 59072 - 970, Natal, RN, Brazil
}

Received: December 05, 2016; Revised: August 31, 2017; Accepted: October 11, 2017

\begin{abstract}
The new generation of cutting fluids should have some characteristics, such as low toxicity and biodegradability. A bio-cutting fluid emulsion are an excellent option because they present those properties, as well as good mechanical performance. The present study aims to investigate the lubricity of $\mathrm{O} / \mathrm{W}$ emulsions (cutting fluid emulsion), varying the concentration of anionic surfactant $(1 \%, 2.5 \%$ and $5 \%)$ and epoxidized oil $(5 \%, 10 \%, 15 \%, 20 \%$ e $25 \%)$. A sunflower oil was chemically modified by epoxidation reaction, then its viscosity, iodine and oxirane index, density, and acidity were characterized. The performances of the emulsions were evaluated using a tribometer HFRR (High Frequency Reciprocating Rig), under hydrodynamic lubrication conditions. The ball wear scars were analyzed using an optical microscopy. The results showed that a low concentration of surfactant promote friction and wear reduction. Based on the tribological performance, the emulsions with 5\% and $10 \%$ of epoxidized oil are more suitable.
\end{abstract}

Keywords: $\mathrm{O} / \mathrm{W}$ emulsion, Epoxidized Vegetal Oil, Tribological Tests, Cutting Fluid Concentration

\section{Introduction}

Cutting fluids are classified as straight, synthetic, semisynthetic and soluble oils. Each one has different properties, and they are selected depending on machining processes requirements ${ }^{1}$.

The main negative effects of petroleum based lubricants are linked to environmental problems generated from their inappropriate use, contaminating surface water, groundwater, air, soil, and consequently, agricultural products, including food $^{2}$. Despite their widespread use, operators can develop serious health problems such as lung cancer, respiratory and dermatological diseases ${ }^{3}$. Therefore, it has been notice a growing interest in development of environmentally friendly cutting fluids.

In this context, vegetable oils are a suitable alternative to replace petroleum based oil, once that they are biodegradable and non-toxic ${ }^{4}$. In fact, vegetable oils have most of the desirable lubrication properties, great lubricants must have low volatility, high viscosity index, easy miscibility with other fluids, reduced toxicity and better performance ${ }^{5}$. However, a high degree of multiple unsaturation of $\mathrm{C}-\mathrm{C}$ in the fatty acid chain of many vegetable oils is responsible for its low temperature and low oxidative stability, which restricts their use as lubricants at a modest temperature range ${ }^{6}$.

In this way, a thermal and oxidant stability improvement of the vegetable oils can be achieved using a chemical modification. Among the methods of chemical modification, the epoxidation reaction is one of the most important functionalization reactions to eliminate the thermal and oxidative instability derived from the presence of unsaturated bonds in vegetable oils ${ }^{7}$. Besides, this process can result in an oil with better anticorrosion properties and greater affinity to the metal surface, presence of oxygen from the oxirane group ${ }^{8}$.

Epoxidized vegetable oils interact easily with the metal surface, due to their polar characteristics, reducing friction and wear ${ }^{9}$

In the cutting fluids formulation, the modified vegetable oils are more than just a biocompatible alternative, due to their biodegradable characteristics, they also have low levels of corrosivity, excellent lubricity, low volatility and good viscosity and temperature characteristics ${ }^{10}$.

In addition, they show excellent physical and chemical adsorption properties due to their chemical structure, promoting the formation of a more resistant lubricating films ${ }^{11}$.

$\mathrm{O} / \mathrm{W}$ emulsions are widely used in tribological applications in order to facilitate operation (cutting or shaping) of metals, especially steel. These emulsions have an important property; they form hydrodynamic films efficiently ${ }^{12}$. The $\mathrm{O} / \mathrm{W}$ emulsions are complex mixtures of water, base oils and additives. The oil phase acts as a lubricant, reducing the friction between workpiece and tool, while the water phase promotes the cooling for different machining processes. This fluid is suitable for turning, milling and grinding process due to the use of new cutting tool materials, such as hard metals and high cutting speeds. It reduce the effect of generated heat on cutting tool wear ${ }^{1}$. 
In the emulsion, the surfactant aid in the oil drop dispersion and influencing in drop size ${ }^{13}$. The smaller the droplets, the better is the drop transport to the metal surface, reducing friction and improving lubricity performance ${ }^{14}$. The objective of this study is to investigate the lubricity of $\mathrm{O} / \mathrm{W}$ emulsion varying the concentration of anionic surfactant and epoxidized oil.

\section{Materials and Methods}

\subsection{Surfactant preparation}

The surfactant used was a mixture of animal fat and coconut oil, with a mass percentage of $95 \%$ and $5 \%$, respectively, synthesized in the laboratory. Table 1 presents the mean composition of fatty acids present in animal fat and coconut oil ${ }^{15}$.

\subsection{Epoxidation of sunflower vegetable oil}

Sunflower oil was epoxidized with formic acid "in situ", using peroxide as oxygen source and sulfuric acid as catalyst, $4 \%(\mathrm{w} / \mathrm{w})$. The molar ratio of hydrogen peroxide/formic acid/ vegetable oil was $11 / 5 / 1$. The reaction occurred by adding formic acid to the sunflower oil, understeering for 30 minutes. Then, hydrogen peroxide was added, drop by drop, per 20 minutes. After this, the mixture was kept under stirring for 5 hours at $50^{\circ} \mathrm{C}$. Then, the organic phase was separated by decantation and washed with distilled water at $70{ }^{\circ} \mathrm{C}$ until reaching a $\mathrm{pH}$ between 6 and 7. Finally, the oily layer was dried in an oven at $90-100{ }^{\circ} \mathrm{C}$ for $4 \mathrm{~h}$. Table 2 presents the mean composition of fatty acids in sunflower oil ${ }^{16}$.

\subsection{Epoxidized sunflower oil characterization}

The physicochemical characterization of epoxidized sunflower oil was performed in triplicate, according to the ASTM standards listed in Table 3.

\subsection{Emulsion Preparation}

The oil in water emulsions were prepared using 5\%, 10\%, $15 \%, 20 \%$ and $25 \%$ (by weight) of epoxidized sunflower oil and $1 \%, 2.5 \%$ and $5 \%$ of surfactant $(5 \%$ coconut oil and $95 \%$ animal fat). The emulsions were prepared at $1500 \mathrm{rpm}$ for 10 minutes.

Table 1. Mean composition (wt.\%) in fatty acids in coconut oil and animal fat.

\begin{tabular}{ccc}
\hline Acid, Carbon number & Coconut oil (wt.\%) & Animal fat (wt.\%) \\
\hline Capric, C10 & 6 & - \\
Lauric, C12 & 47 & 5 \\
Myristic, C14 & 18 & 29 \\
Palmitic, C16 & 9 & 15 \\
Stearic, C18 & 3 & 36 \\
Oleic, C18 $=$ & 6 & 1.5 \\
Linoleic, $\mathrm{C} 18,2=$ & 2 & 3 \\
Palmitoleic C16= & 6 & 3 \\
\hline
\end{tabular}

Table 2. Fatty acid concentrations in sunflower oil.

\begin{tabular}{cc}
\hline Fatty acids (\%) & Sunflower oil \\
\hline Myristic C14:0 & TRACE \\
Palmitic C16:0 & 6.18 \\
Palmitoleic C16:1 & TRACE \\
Stearic C18:0 & 3.41 \\
Oleic C18:1 & 25.60 \\
Ricinoleic C18:1:OH & TRACE \\
Linileic C18:2 & 64.80 \\
Linilenic C18:3 & TRACE \\
Arachidic C20:0 & TRACE \\
Lignoceric C24:0 & TRACE \\
\hline
\end{tabular}

Table 3. ASTM standards used to determine each property of epoxidized and commercial sunflower oil.

\begin{tabular}{ccccccc}
\hline Property & Viscosity & Viscosity index & Density & Acidity & Iodine value & Oxirane index \\
\hline Standard & $\mathrm{D} 445^{17}$ & $\mathrm{D} 2270^{18}$ & $\mathrm{D} 1298^{19}$ & $\mathrm{D}^{19} 64^{20}$ & AOCS Cd $1-25^{21}$ & $\mathrm{D} 1652^{22}$ \\
\hline
\end{tabular}




\subsection{Evaluation of tribological performance of emulsions}

The tribological performance tests of $\mathrm{O} / \mathrm{W}$ emulsions were evaluated in High Frequency Reciprocating Rig (HFRR). The tests conditions were based on ASTM standard D6079-04 ${ }^{23}$.

This test consists of ball disc to measure friction and wear under boundary lubricating conditions. The description of the tribological pair is presented in Table 4, both the ball and the disc were made of AISI 52100 steel, which chemical compositions were determined using a X-Ray Fluorescence (XRF), Table 5. The tribological pair was subjected to a condition of $2 \mathrm{~N}, 50 \mathrm{~Hz}$ and submerged into $2 \mathrm{ml}$ of the emulsion during $75 \mathrm{~min}$ at a constant temperature of 60 ${ }^{\circ} \mathrm{C}$. The tribological pair (ball and disc) were cleaned by immersion in toluene for 7 minutes, dried with hot air and then immersed for 3 minutes in acetone. Each test was performed in triplicate in order to provide an average coefficient of friction reported in this study. Table 4 shows the physical characteristics of the tribological pair (ball and disc).

\subsection{Ball Wear Analysis}

The standards that evaluate the lubricity of a lubricant only consider the diameter of the wear scar calculated from its size ( $\mathrm{X}$ and $\mathrm{Y}$ ) analyzed in a light microscope, without observing the morphology of the wear. Therefore, it is important to analyze the image of the ball after testing the HFRR.

\section{Results and Discussion}

\subsection{Epoxidized sunflower oil characterization}

The physicochemical analysis of biolubricant properties (Density, Acidity, Iodine Index, Oxirane Index, Viscosity and Viscosity Index) are presented and compared with the commercial oil properties in Table 6 . These properties are very important for evaluating the lubricant quality.

According to Anvisa ${ }^{24}$, the density of sunflower oils should be between $0.9150-0.9200 \mathrm{~g} / \mathrm{cm}^{3}$ at $25^{\circ} \mathrm{C}$. Thus, for the sunflower bio-lubricant, it was observed that its density is little higher than the obtained for commercial sunflower oil. This increase is due to the epoxidation reaction, which modifies its physical and chemical properties ${ }^{25}$.

The efficiency of the epoxidation reaction was determined by iodine index, a parameter used to indicate the presence of double bonds in a fatty acid ester, which corresponds to the number of centigrams of iodine absorbed per 1 gram of fat. The higher the index value, the greater the degree of unsaturation, indicating the vegetable oil tendency to oxidize, low values indicate epoxidation efficiency ${ }^{26}$. As noted in Table 6 , there was a significant reduction, $119.77 \mathrm{~g}$ of $\mathrm{I}_{2} / 100 \mathrm{~g}$ of Sunflower oil to $1.3 \mathrm{~g}$ of $\mathrm{I}_{2} / 100 \mathrm{~g}$ of epoxidized oil, indicating the epoxidation process efficiency ${ }^{27}$.

The biolubricant presented a higher acid number when compared with the sunflower oil, which is caused by the residual acid from the epoxidation reaction. A high acidity aid reducing the lubricant conservation status, increasing wear and corrosiveness in the mechanical parts and equipment ${ }^{28}$. However, the acidity values of the epoxidized oil are adequate to the use it as lubricant.

The biolubricant showed higher viscosity values (Table 6) compared to the commercial sunflower oil. It is important to consider that the viscosity allows a good atomization of the oil and preserves its characteristic as a lubricant. This increase in viscosity is due to conversion reaction of unsaturation bonds in oxirane rings ${ }^{29}$. The emulsions viscosities were measured, and all developed $\mathrm{O} / \mathrm{W}$ emulsions presented similar values, the average viscosity was of $\pm 0.292 \mathrm{cP}$ with standard deviation of \pm 0.0265 .

Table 4. The physical characteristics of the tribological pair.

\begin{tabular}{ccc}
\hline & Ball & Disc \\
\hline Hardness $(\mathrm{HV})$ & $(570-750)$ & $(190-210)$ \\
Dimensions & Diameter $=6.0 \mathrm{~mm}$ & Diameter $=10.0$ mmThickness $=3.0 \mathrm{~mm}$ \\
RoughnessRa $(\mu \mathrm{m})$ & 0.05 & 0.02 \\
\hline
\end{tabular}

Table 5. Chemical composition by weight (\% p.) from the AISI 52100 steel disc.

\begin{tabular}{cccccccc}
\hline $\mathrm{Fe}$ & $\mathrm{C}$ & $\mathrm{Mn}$ & $\mathrm{Cr}$ & $\mathrm{S}$ & $\mathrm{Si}$ & $\mathrm{Al}$ & $\mathrm{Ca}$ \\
\hline $\mathrm{Bal}$ & 0.900 & 0.413 & 1.567 & 0.127 & 0.546 & 0.105 & 0.154 \\
\hline
\end{tabular}

Table 6. Physicochemical Properties of Epoxidized and Commercial Sunflower oil.

\begin{tabular}{ccccccc}
\hline Analysis & Density $\left(\mathrm{g} / \mathrm{cm}^{3}\right)$ & $\begin{array}{c}\text { Acidity }(\mathrm{mg} \\
\mathrm{KOH} / \mathrm{g})\end{array}$ & $\begin{array}{c}\text { Iodine index }(\mathrm{g} \\
\left.\mathrm{I}_{2} / 100 \mathrm{~g} \text { fat }\right)\end{array}$ & $\begin{array}{c}\text { Oxirane index } \\
(\%) \mathrm{m} / \mathrm{m}\end{array}$ & $\begin{array}{c}\text { Viscosity }(\mathrm{cSt}) \\
\text { at } 40^{\circ} \mathrm{C} \text { and } \\
100^{\circ} \mathrm{C}\end{array}$ & $\begin{array}{c}\text { ViscosityIndex } \\
\text { OGC }\end{array}$ \\
OGEAF & 0.9183 & \pm 0.08 & 119.77 & - & $27 / 11.5$ & 147 \\
\hline
\end{tabular}

Legend: OGEAF (Epoxidized Sunflower Oil with Formic Acid); OGC (Commercial Sunflower Oil). 
Viscosity index (VI) is a number that indicates the viscosity variation of an oil when the temperature is changed. A higher viscosity index indicates small changes in viscosity in large range of temperature, whereas low values indicate high variations of viscosity ${ }^{30}$. The bio-lubricants based on epoxidized oils have higher VI (about 155), meaning good efficiency at high temperatures, keeping its thickness ${ }^{31}$.

The conversion value (C) of unsaturation bonds was $59.65 \%$. This conversion value was obtained by the relation between the experimental value (OOexp) and theoretical oxirane oxygen (OOth), which corresponds the maximum theoretical value of oxirane oxygen that can be obtained in $100 \mathrm{~g}$ of oil ${ }^{32}$.

\subsection{Evaluation of the tribological performance of emulsions}

The friction coefficients for all developed $\mathrm{O} / \mathrm{W}$ emulsions are presented in Figure $1 \mathrm{~A}-\mathrm{E}$, while Table 7 shows the average coefficient of friction. In Figure $1 \mathrm{~A}-\mathrm{B}$, the friction coefficient (COF) features smaller values for emulsions developed with $5 \%$ and $10 \%$ of epoxidized oil and low concentration of surfactant (1\%). While higher surfactant $(2.5 \%$ and $5 \%)$ and epoxidized oil $(15 \%, 20 \%$ and $25 \%)$ concentrations promote a significant increase in the COF, especially for emulsions with 5\% surfactant. However, all emulsions with $5 \%$ surfactant presented an increase in COF independent of the epoxidized oil concentration. Probably, the performance of surfactant in the emulsion guarantees its stability because it forms smaller droplets, although its excessive increase competes with the oil on surface adsorption, decreasing the emulsion lubricity ${ }^{33}$.

Figure 2 A-E shows the film formation behavior of $\mathrm{O} / \mathrm{W}$ emulsions studied during the HFRR test through the ECR (electric contact resistance). The film formation for the emulsion developed with $1 \%$ surfactant (figure $2 \mathrm{~A}-\mathrm{E}$ ) shows an efficient film formation, around $95 \%$, and stable throughout the essay, unlike the other concentrations of $2.5 \%$ and $5 \%$ of surfactant. Probably this behavior can be explained by the surfactant characteristic (anionic), which has a tendency to adsorb on metal surfaces more efficiently, resulting in greater film formation. The functional group of the surfactant establishes a stronger interaction with the metallic surface and, therefore, a stable lubricant film ${ }^{34}$. It forms a monolayer micelle, which increases the efficiency of the metal cover and can increase the coefficient of friction due to shear strength, known as fluid friction ${ }^{35}$. Thus, in some cases, as noted in Figure 1B, the behavior of film formation was not directly proportional to the friction coefficient values. Highest values were observed for COF $5 \%$ surfactant, which provide better formation.

When the concentration of epoxidized oil increases $(15 \%, 20 \%$ and $25 \%)$, Figure $2 \mathrm{C}-\mathrm{D}-\mathrm{E}$, it is observed that the formation of the film was unstable over time, regardless the variation in the concentration of surfactant. In addition,

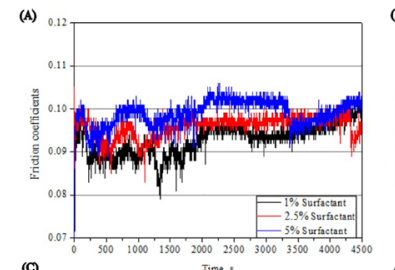

(C)
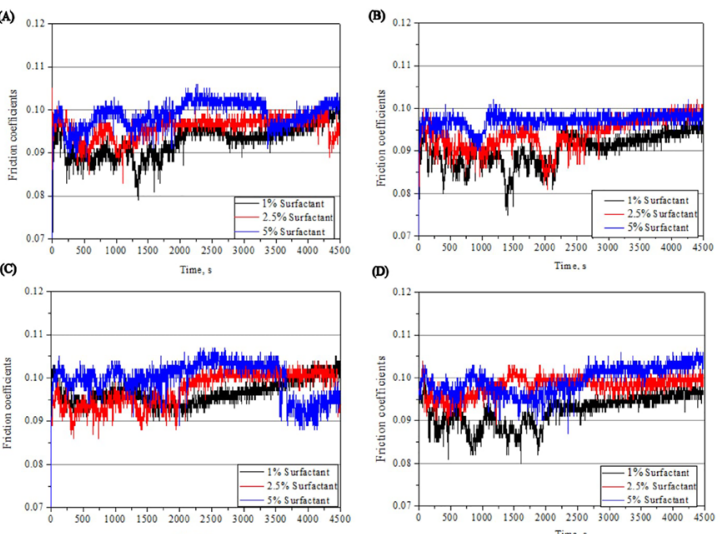

(D)
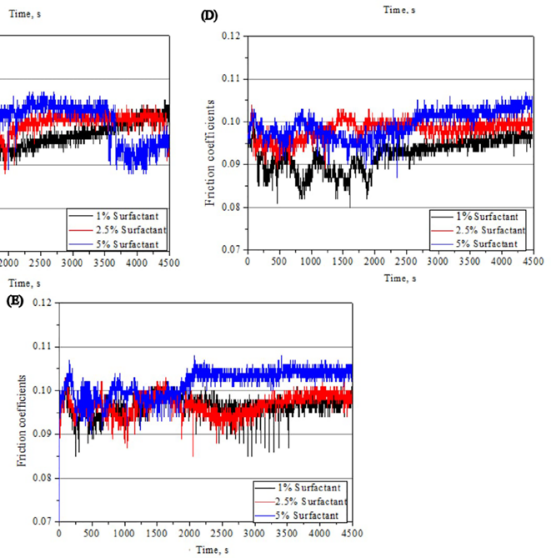

Figure 1. Coefficient of friction of $\mathrm{O} / \mathrm{W}$ emulsions: (A) $5 \%$ epoxidized oil; (B) 10\% epoxidized oil (C) 15\% epoxidized oil; (D) 20\% epoxidized oil; (E) 25\% epoxidized oil.

Table 7. Average friction coefficient in the HFRR test.

\begin{tabular}{ccc}
\hline & Emulsion O/W & \\
\hline \multirow{2}{*}{ Epoxidized oil } & Surfactant & $\begin{array}{c}\text { Average coefficient } \\
\text { of friction }\end{array}$ \\
\hline $5 \%$ & $1 \%$ & 0.088 \\
& $2.5 \%$ & 0.091 \\
$10 \%$ & $5 \%$ & 0.092 \\
& $1 \%$ & 0.089 \\
& $2.5 \%$ & 0.092 \\
& $5 \%$ & 0.097 \\
& $1 \%$ & 0.091 \\
& $2.5 \%$ & 0.093 \\
& $5 \%$ & 0.098 \\
& $1 \%$ & 0.092 \\
& $2.5 \%$ & 0.094 \\
& $5 \%$ & 0.099 \\
& $1 \%$ & 0.096 \\
& $2.5 \%$ & 0.096 \\
& $5 \%$ & 0.102 \\
\hline
\end{tabular}

this instability in the formation of the film can be explained by the formation and rupture of the monolayer metal due to friction (reciprocating movement), confirming the highs COF values, as is observed in Figure 1 C-D-E.

In Figure 3, show the results of the wear scar diameter (WSD) for the studied O/W emulsions. All values of WSD, in Figure 3, are in accordance with the European regulations ${ }^{36}$, less than $460 \mu \mathrm{m}$. 
(A)
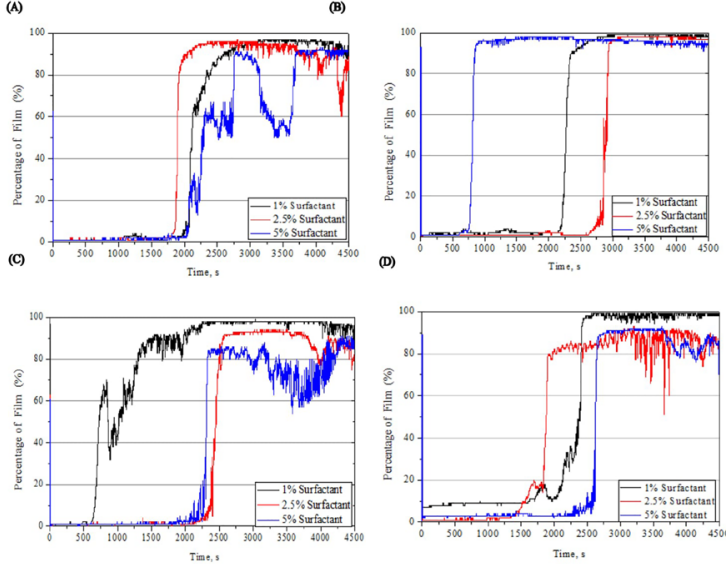

(E)

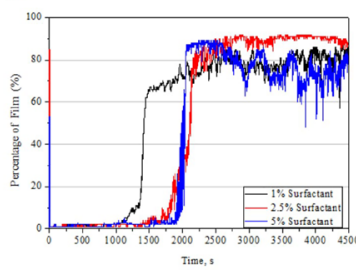

Figure 2. Film forming of O/W emulsions: (A) 5\% epoxidized oil; (B) $10 \%$ epoxidized oil (C) $15 \%$ epoxidized oil; (D) $20 \%$ epoxidized oil; (E) $25 \%$ epoxidized oil.

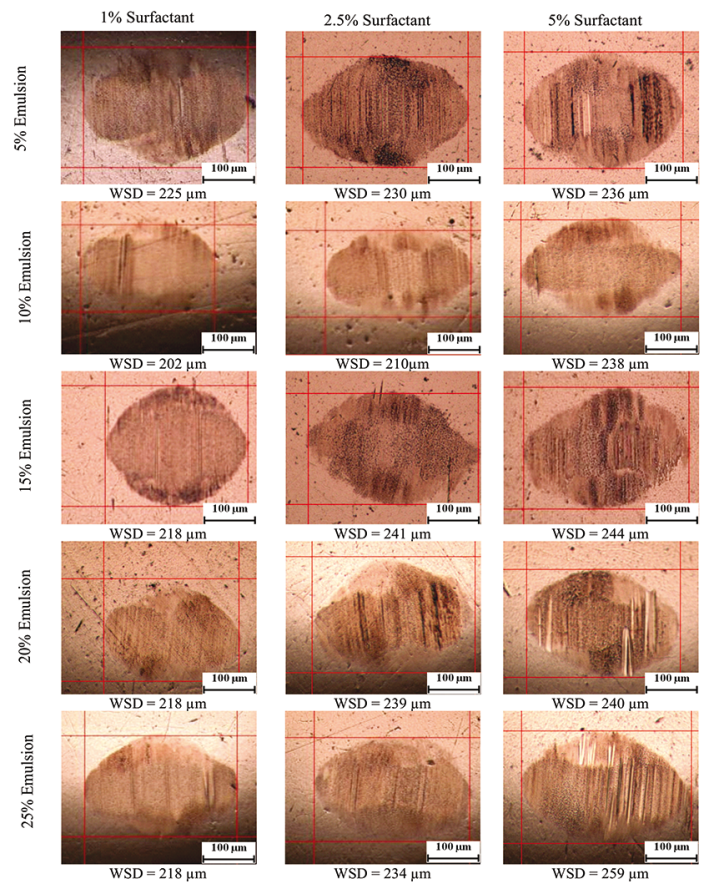

Figure 3. Images of the wear scars on the AISI 52100 steel ball. Average scar diameter measured for emulsion with $5 \%, 10 \%, 15 \%$, $20 \%$ and $25 \%$ epoxidized oil varying surfactant (A) $1 \%$ surfactant (B) $2.5 \%$ surfactant (C) 5\% surfactant. Magnification: 100 times.

Analyzing the images WSD in Figure 3, the emulsions with $5 \%, 10 \%, 20 \%, 15 \%$ and $25 \%$ of epoxidized oil showed a slight tendency to increase the WSD in the ball as the surfactant concentration increases $(1 \%, 2.5 \%$ and $5 \%)$. All emulsions with $1 \%$ surfactant concentration presented a minor WSD when compared with the others $(2.5 \%$ and $5 \%$ ). The images showed signs of lighter grooves, indicating that wear did not increased, being more uniform, with few apertures. In addition to the lowest WSD, signs of oxidation (dark spots). It is observed that the grooves are more intense on the surface of the ball with the largest concentrations of surfactant $(5 \%)$. Probably these grooves may have been caused by hard particles, probably oxides, which increases the friction between the surfaces, promoting this wear ${ }^{37}$.

Another important observation is that an increase in the oil concentration does not promote a significant WSD reduction. Analyzing the Figure 3 , at $1 \%$ surfactant, when the concentration of epoxidized oil is increased $4 \times(5 \%$ to $20 \%)$ there was a $3 \%$ reduction in the value of WSD ( 225 to $218 \mu \mathrm{m}$ ), which leads to the conclusion that for oil concentration range studied there is a directly trend between WSD and percentage of oil.

\section{Conclusion}

The present study analyzed the effect of surfactant and epoxidized oil concentration on tribological properties in $\mathrm{O} / \mathrm{W}$ emulsion development. Based on the results presented above, it is possible to conclude that:

- The physicochemical properties analyzed are suitable for the fluid lubricants.

- The lowest concentration of surfactant (1\%) presented lower friction and WSD coefficients in the studied emulsions. Once that the surfactant in the medium stabilized the emulsion, forming smaller droplets.

- The emulsions with $5 \%$ surfactant showed higher friction and WSD coefficients values. This occurs because the surfactant competes with the oil on the surface, decreasing the lubricity in the medium.

- The highest concentrations of epoxidized oil showed a slow and unstable film, as well as greater values of the coefficient of friction and WSD.

Therefore, the emulsions that showed the best tribological performance to cutting fluid emulsion were the emulsions with $5 \%$ and $10 \%$ of epoxidized oil and $1 \%$ of surfactant concentration.

\section{Acknowledgements}

The authors acknowledge the engineers and technicians of the Chemical Technology, NUPEG II, and the Tribology laboratories for their assistance in the present work.

\section{References}

1. Liew PJ, Shaaroni A, Chesidik NAC, Yan J. An overview of current status of cutting fluids and cooling techniques of turning hard steel. International Journal of Heat and Mass Transfer. 2017;114:380-394. 
2. Ozcelik B, Kuram E, Cetin MH, Demirbas E. Experimental investigations of vegetable based cutting fluids with extreme pressure during turning of AISI 304L. Tribology International. 2011;44(12):1864-1871.

3. Shashidhara YM, Jayaram SR. Vegetable oils as a potential cutting fluid-An evolution. Tribology International. 2010;43(56):1073-1081.

4. Campanella A, Rustoy E, Baldessari A, Baltanás M. Lubricants from chemically modified vegetable oils. Bioresource Technology. 2010;101(1):245-254.

5. Salimon J, Salih N, Yousif E. Chemically modified biolubricant basestocks from epoxidized oleic acid: Improved low temperature properties and oxidative stability. Journal of Saudi Chemical Society. 2011;15(3):195-201.

6. Sharma BK, Adhvaryu A, Liu Z, Erhan SZ. Chemical modification of vegetable oils for lubricant applications. Journal of the American Oil Chemists' Society. 2006;83(2):129-136.

7. Kleinová A, Fodran P, Brnčalová L, Cvengroš J. Substitute esters of stearic acid as potential lubricants. Biomass and Bioenergy. 2007;32(4):366-371.

8. Wu X, Zhang X, Yang S, Chen H, Wang D. The study of epoxidized rapessed oil used as a potential briodegradable lubricant. Journal of the American Oil Chemists' Society. 2000;77(5):561-563.

9. John J, Bhattacharya M, Raynor PC. Emulsions containing vegetable oils for cutting fluid application. Colloids and Surfaces A: Physicochemical and Engineering Aspects. 2004;237(13):141-150.

10. Cambiella A, Benito JM, Pazos C, Coca J, Hernández A, Fernández JE. Formulation of emulsifiable cutting fluids and extreme pressure behaviour. Journal of Materials Processing Technology. 2007;184(1-3):139-145.

11. Adhvaryu A, Erhan SZ, Perez JM. Tribological studies of thermally and chemically modified vegetable oils for use as environmentally friendly lubricants. Wear. 2004;257(3-4):359367.

12. Kumar D, Biswas SK. Effect of surfactant dispersed in oil on interaction force between an oil film and a steel substrate in water. Colloids and Surfaces A: Physicochemical and Engineering Aspects. 2011;377(1-3):195-204.

13. Kumar D, Daniel J, Biswas SK. Tribology of steel/steel interaction in oil-in-water emulsion; a rationale for lubricity. Journal of Colloid and Interface Science. 2010;345(2):307-315.

14. Wang J, Jing H, Wang Y. Possible effects of complex internal structures on the apparent viscosity of multiple emulsions. Chemical Engineering Science. 2015;135:381-392.

15. Melo RPF, Barros Neto EL, Moura MCPA, Dantas TNC, Dantas Neto AA, Oliveira HNM. Removal of direct Yellow 27 dye using animal fat and vegetable oil-based surfactant. Journal of Water Process Engineering. 2015;7:196-202.

16. Quinchia LA, Delgado MA, Valencia C, Franco JM, Gallegos C. Viscosity modification of different vegetable oils with EVA copolymer for lubricant applications. Industrial Crops and Products. 2010;32(3):607-612.
17. ASTM International. ASTM D445-97 - Test Method for Kinematic Viscosity of Transparent and Opaque Liquids (the Calculation of Dynamic Viscosity). West Conshohocken: ASTM International; 1997.

18. ASTM International. ASTM D2270-93 - Standard Practice for Calculating Viscosity Index From Kinematic Viscosity at 40 and $100^{\circ} \mathrm{C}$. West Conshohocken: ASTM International; 1998 .

19. ASTM International. ASTM D-1298-99-Standard Test Method for Density, Relative Density (Specific Gravity) or API Gravity of Crude Petroleum and Liquid Petroleum Products by Hydrometer Method. Section 5. West Conshohocken: ASTM International; 1999.

20. ASTM International. ASTM D 664-01 - Standard Test Method for Acid Number of Petroleum Products by Potentiometric Titration. West Conshohocken: ASTM International; 2001.

21. American Oil Chemists' Society (AOCS). Official Methods and Recommended Practices of the American Oil Chemists' Society. $4^{\text {th }}$ ed. (AOCS Recommended Practice Cd 1-25). Champaign: AOCS; 1995.

22. ASTM International. ASTM D1652-97 - Standard Test Methods for Epoxy Content of Epoxy Resins. West Conshohocken: ASTM International; 1997.

23. ASTM International. ASTM D6079-04 - Standard Test Method for Evaluating Lubricity of Diesel Fuels by the High-Frequency Reciprocating Rig (HFRR). West Conshohocken: ASTM International; 2004.

24. Brazil. Ministry of Health. Agência Nacional de Vigilância Sanitária - Anvisa. Resolução n. 482, de 23 de setembro de 1999. Diário Oficial da União. 2000 Jun 20. Available from: http://portal.anvisa.gov.br/documents/10181/2718376/ RES_482_1999_COMP.pdf/0b31ce35-6d43-42d6-8184549 de 494987 a? version=1.0 $>$. Access in: 25/09/2014.

25. Trajano MF, Moura EIF, Ribeiro KSB, Alves SM. Study of oxide nanoparticles as additives for vegetable lubrican. Materials Research. 2014;17(5):1124-1128.

26. Silva MS, Foletto EL, Alves SM, Dantas TNC, Dantas Neto AA. New hydraulic biolubricants based on passion fruit and moringa oils and their epoxy. Industrial Crops and Products. 2015;9:362-370.

27. Farias M. Síntese, caracterização de catalisadores e estudo de suas atividades catalíticas na epoxidação de óleos vegetais. [Thesis]. Porto Alegre: Universidade Federal do Rio Grande do Sul; 2010.

28. Muniz CAS. Novas formulações de fluidos de corte: otimização, propriedades e recuperação do óleo usado. [Thesis]. Natal: Universidade Federal do Rio Grande do Norte; 2008.

29. Knothe G. Dependence of biodiesel fuel properties on the structure of fatty acid alkyl esters. Fuel Processing Technology. 2005;86(10):1059-1070.

30. Erhan SZ, Sharma BK, Liu Z, Adhvaryu A. Lubricant Base Stock Potential of Chemically Modified Vegetable Oils. Journal of Agricultural and Food Chemistry. 2008;56(19):8919-8925.

31. Mobarak HM, Mohamad EN, Masjuki HH, Kalam MA, Al Mahmud KHA, Habibullah M, et al. The prospects of biolubricants as alternatives in automotive applications. Renewable and Sustainable Energy Reviews. 2014;33:34-43. 
32. Mungroo R, Pradhan NC, Goud VV, Dalai AK. Epoxidation of Canola Oil with Hydrogen Peroxide Catalyzed by Acidic Ion Exchange Resin. Journal of the American Oil Chemists' Society. 2008;85(9):887-896.

33. Larsson R, Kassfeldt E, Byheden A, Norrby T. Base fluid parameters for EHL and friction calculations and their influence on lubrication capability. $12^{\text {th }}$ International Colloquium, Technische Akademie Esslingen. Proceedings of the Tribology. 2000;2:1525-1536.

34. Ma L, Luo J, Zhang C, Liu S, Lu X, Guo D, et al. Film forming characteristics of oil-in-water emulsion with super-low oil concentration. Colloids and Surfaces A: Physicochemical and Engineering Aspects. 2009;340(1-3):70-76.
35. Upadhyay RK, Kumaraswamidhas LA. On the influence of surfactant over friction properties of steel. Chemical Physics Letters. 2014;608:167-172.

36. European Committee for Standardization. EN-590: automotive fuels diesel requirements and test methods. Brussels: European Committee for Standardization; 2009.

37. Alves SM, Barros BS, Trajano MF, Ribeiro KSB, Moura E. Tribological behavior of vegetable oil-based lubricants with nanoparticles of oxides in boundary lubrication conditions. Tribology International. 2013;65:28-36. 